\title{
QUESTÕES METODOLÓGICAS DA PESQUISA NO CAMPO DA SAÚDE ${ }^{1}$
}

Neusa Collet ${ }^{2}$

Célia Alves Rozendo ${ }^{3}$

Collet N, Rozendo CA. Questões metodológicas da pesquisa no campo da saúde. Rev Latino-am Enfermagem 2001 maio; 9(3):106-11.

Este trabalho tem por objetivo apresentar reflexão sobre o método de pesquisa no campo da saúde. Algumas questões que envolvem o emprego do método das ciências naturais e o método das ciências sociais são apresentadas, buscando compreender alguns problemas metodológicos de um e de outro. Problemas relacionados às questões metodológicas na elaboração de um projeto de investigação são pontuados: diferenciação da natureza do objeto de investigação; contexto em que determinado problema é identificado; tipo de pergunta ao problematizá-lo; procedimentos técnicos, teoria e esquema interpretativo; dicotomia sujeito/objeto do conhecimento; neutralidade do pesquisador; conceito de causalidade.

UNITERMOS: pesquisa, saúde, metodologia

\section{METHODOLOGICAL ISSUES CONCERNING RESEARCH IN THE HEALTH FIELD}

This work aims at presenting a reflection on the method of research in the health field. Some questions are presented which involve the use of the method of natural sciences and that of social sciences in an attempt at understanding some methodological problems concerning the former and the latter. Problems related to the methodological issues in the elaboration of investigation projects in this field and the need for continuous discussion are pointed out as to: the differentiation of the nature of the object of investigation; the context in which a determined problem is identified; the type of question which is asked when it is problematized; technical procedures, the theory and the interpretative scheme on which it is founded; the dichotomy concerning the subject/object of knowledge; the researcher's neutrality; the concept of casuality.

KEY WORDS: research, health, methodolology

\section{ASPECTOS METODOLÓGICOS DE LA INVESTIGACIÓN EN EL CAMPO DE LA SALUD}

Este trabajo tiene como objetivo presentar una reflexión sobre el método de investigación en el campo de la salud. Presentamos algunas cuestiones que encierran el empleo de las ciencias naturales y el método de las ciencias sociales, tratando de esclarecer algunos problemas metodológicos tanto de uno como del otro. Abordamos problemas relacionados con los aspectos metodológicos para la elaboración de un proyecto de investigación que necesitan ser continuamente discutidos, incluyendo: la diferenciación de la naturaleza del objetivo de la investigación, el contexto en que determinado problema es identificado, el tipo de pregunta que se hace al problematizarlo, los procedimientos técnicos, la teoría y el esquema interpretativo que lo fundamentan; la dicotomía sujeto/objeto del conocimiento, la neutralidad del investigador, el concepto de causalidad.

\section{TÉRMINOS CLAVES: investigación, salud, metodología}

\footnotetext{
${ }^{1}$ Trabalho de conclusão de curso apresentado na disciplina Problemas Conceituais e Metodológicos de Investigação em Medicina Social da Faculdade de Medicina de Ribeirão Preto da Universidade de São Paulo

${ }^{2}$ Enfermeira, Professor Assistente do Departamento de Enfermagem da Universidade Estadual do Oeste do Paraná - UNIOESTE, Doutoranda do Programa Interunidades de Doutoramento em Enfermagem na Escola de Enfermagem de Ribeirão Preto da Universidade de São Paulo. E-mail: ncollet@certto.com.br ${ }^{3}$ Enfermeira, Professor Assistente do Departamento de Enfermagem da Universidade Federal de Alagoas - UFAL, Doutor em Enfermagem pela Escola de Enfermagem de Ribeirão Preto da Universidade de São Paulo. E-mail: carozendo@uol.com.br
} 


\section{INTRODUÇÃO}

$\boldsymbol{A}$ marca fundamental da ciência nos diversos momentos da história é a tentativa de explicar, descobrir as leis que regem os fenômenos. Ao fazer essa tentativa, a relação do homem com 0 conhecimento torna-se uma "relação em que o homem passa, por assim dizer, a ter o fenômeno em suas mãos, o que, em última instância, the permite interferir naquilo que conhece" ${ }^{\text {(1) }}$.

Entretanto, só esta marca não nos permite conhecer a história da ciência, o seu desenvolvimento, pois ela assume um significado diferente em cada momento histórico. E é o reconhecimento dessas diferenças e suas raízes que nos permite compreender como a ciência se apresenta em nosso século. Entendemos que reconhecer a ciência como tentativa de explicar racionalmente os fenômenos está vinculado a nossa compreensão acerca do conhecimento científico, ou seja, compreender a "ciência como atividade humana em que o homem busca conhecer o mundo e nele intervir, atividade que está presente em toda a história humana, fazendo parte integrante dela, desde o momento em que esse conhecimento, de uma origem prática, passa a ser elaborado com algum grau de abstração. Ao mesmo tempo, vincula-se ao entendimento da ciência como uma atividade humana que não permanece idêntica, porque é historicamente determinada, que é produto do homem em condições históricas dadas, que se transforma à medida que o homem se transforma e que, simultaneamente, interfere na própria história” ${ }^{(1)}$.

Falar da construção do conhecimento pressupõe falar de uma de suas características fundamentais - o método. Ao construir o caminho em direção à explicação dos fenômenos o método expressa concepç̃̃es de homem, de natureza, de sociedade, de história e de conhecimento que trazem a marca do momento histórico em que o conhecimento é produzido ${ }^{(1)}$.

Quando a metodologia da pesquisa aparece como um dos problemas a ser enfrentado no campo da saúde, encontra-se um universo de referências de abordagens que aparecem na literatura, e nas discussões em geral, com uma variedade de enfoques e conteúdos. Essas transformações não foram linearmente cumulativas, nem foram únicas ou homogêneas num mesmo período, mas se expressaram por meio do embate de diferentes posturas e concepções.

Nosso objetivo, neste trabalho, é o de buscar compreender questões gerais que envolvem o emprego do método das ciências naturais e o método das ciências sociais, apontando alguns dos problemas metodológicos que os envolvem. Pautaremos a apresentação referenciando autores que discutiram estas questões numa perspectiva de compreensão da aplicabilidade de um e de outro na campo da saúde.
Inicialmente fazemos uma breve abordagem do surgimento da medicina social tendo em vista ter sido esta a pioneira em problematizar e apontar a importância do papel dos fatores sociais para a compreensão dos problemas de investigação no campo da saúde. Apresentamos, genericamente, alguns problemas relacionados às questões metodológicas neste campo, buscando levantar alguns aspectos relevantes, no nosso entender, na elaboração de um projeto de investigação científica.

\section{A MEDICINA SOCIAL E O MÉTOdO DE INVESTIGAÇÃO}

A discussão inicial gira em torno do método capaz de imprimir à investigação no campo da saúde, o conhecimento do seu objeto de trabalho. As dificuldades começam quando surgem as ciências sociais, aquelas cujo objeto de trabalho é a sociedade, pois não se pode estudar problemas sociais como se fossem objetos isolados. Só se pode compreender o social como totalidade de significação, pois a sociedade não tem um limite que a separe de tudo o mais já que ela própria é o todo.

0 movimento de preocupação com o social na saúde tem sua formação na Europa com: a) a medicina do Estado no começo do século XVIII, na Alemanha; b) a medicina urbana em fins do século XVIII, na França; e c) a medicina da força de trabalho ou dos pobres, na Inglaterra ${ }^{(2)}$.

As origens do pensamento social em saúde têm suas bases nos movimentos europeus de reforma sanitária e reforma médica na segunda metade do século XIX. Estes movimentos trazem consigo idéias liberais e a consciência da importância do papel dos fatores sociais para a compreensão dos problemas de saúde. Os fatores sociais que influenciam o campo da saúde vão para além do biológico, estando relacionados às questões econômicas, políticas e ideológicas na configuração de suas propostas. Um segundo momento, diz respeito ao reordenamento da prática médica a partir do final da Segunda Guerra Mundial por meio da formação médica, criando uma nova atitude preventivista ${ }^{(3)}$.

Até a década de 50 a medicina preventiva estava centrada no indivíduo e a concepção era de uma relação dual médico-indivíduo. Os fundamentos eram os fatores relacionados ao risco (risco-dano). A partir da Conferência de Alma-Ata, o foco passa a ser a atenção primária com a finalidade de prevenir doenças não mais com atuação sobre o biológico, mas por meio da extensão de cobertura levando a saúde para onde a população estivesse.

$\mathrm{Na}$ década de 70 a ênfase continua na atenção primária tendo as práticas coletivas como principal referência. Buscava-se entender a determinação estrutural da produção e distribuição da 
doença e das relações entre a organização de ações de saúde e as formações sócio-econômicas.

Nas décadas de 70 e 80 a medicina comunitária se expande e a saúde não fica mais somente interna ao próprio setor, mas ampliase envolvendo os problemas habitacionais, de alimentação, e outros relacionados a condições de vida. As ciências que fundamentam este novo conhecimento é o planejamento e a administração em saúde, baseado em política, ciências sociais, epidemiologia social além daquele que até então fundamentou as ações em saúde, a biologia. É neste contexto que emergem no campo da saúde um universo de abordagens teórico-metodológicas que buscam dar conta de apreender a dinâmica que envolve as questões de saúde da população em geral.

\section{É a medicina social que desencadeia essa discussão no campo} da saúde na tentativa de superar a abordagem centrada no biológico numa perspectiva mais ampla do processo saúde-doença. Os fundamentos dessa perspectiva são os das ciências sociais e da filosofia.

0 caminho percorrido pela medicina social imprimiu novas concepções acerca do processo saúde-doença no campo da saúde. Sendo assim, busca-se uma abordagem que dê conta de compreender a complexificação cada vez maior das questões que envolvem a saúde da população, não mais com enfoque restrito ao biológico, mas tentando abarcar o todo que a determina. Não mais uma abordagem interna ao setor saúde, mas buscando a ação intersetorial e a complementaridade, para tratar dos problemas complexos apreendidos.

\section{O MÉTODO NAS CIÊNCIAS}

Para compreendermos os problemas metodológicos no campo da saúde acreditamos ser importante revisitar a introdução do método nas ciências bem como a concepção que se tinha de seu uso, passando pelos principais filósofos que discutiram essa questão. Para tanto, o ponto de partida será a Filosofia Moderna onde os estudiosos da época começam a se preocupar com o método para se chegar ao conhecimento. Tal opção deve-se ao fato de que as influências teórico-metodológicas percebidas até então na produção do conhecimento no campo da saúde datam deste período.

A ciência moderna surge por volta do século XVII com Galileu (1564-1642) apresentando uma visão de mundo mecanicista. Para ele a construção do conhecimento dava-se com a matematização dos fenômenos, o uso da observação e da experiência. Newton (1642-1727) apresenta duas leis de movimento: a força centrípeta e a lei da gravitação universal. Galileu e Newton perceberam as dimensões matemáticas e geométricas dos fenômenos da natureza e propuseram leis de movimento (leis mecânicas). Outros pensadores deste período também se preocuparam com as leis de movimento, como Descartes (15961650) que defende a noção de idéias inatas como fontes de verdades e os sentidos como fontes de ilusão e engano; a razão é a ordem programada. Hobbes (1588-1679) que amplia o campo de abrangência do modelo mecanicista estendendo-o para o próprio conhecimento; e Locke (1652-1704) que afirma que todo conhecimento provém da experiência sensível ${ }^{(1)}$.

A utilização da razão, de dados sensíveis e da experiência, são traços que marcam o trabalho dos pensadores deste período (Filosofia Moderna). Transferem as preocupações das relações homemDeus para as relações homem-natureza. A observação e a experimentação é que dão caráter de verdadeiro ao conhecimento ${ }^{(1)}$.

$\mathrm{Na}$ Filosofia Moderna, o saber contemplativo da era medieval passa a ser operativo (experimentação); da qualidade passa-se a valorizar a quantidade; ocorre uma geometrização do conhecimento e efetivação das relações mecânicas evidenciandose a causa e o efeito dos fenômenos. É neste período que se origina a preocupação com o método na maneira do pensamento e 0 fundamental do método é saber se ele é verdadeiro. Para isso precisa-se de uma ordem e de uma medida. 0 método é sempre considerado matemático e possui esses dois elementos fundamentais: a ordem e a medida. Conhecer é relacionar, é estabelecer um nexo causal, discernir identidades e diferenças entre os seres. A medida oferece o critério para essa identidade e essa diferença. A ordem sistematiza o que foi analisado pela medida, estabelece qual o termo que se relaciona com o outro e qual a seqüência necessária. A ordem é essencial ao método. A idéia de razão é fortemente colocada: só a razão conhece e somente ela pode julgar-se a si mesma. 0 homem tem capacidade reflexiva, tem uma "Luz Natural" que faz com que seja capaz de conhecer o caminho independente da fé. É uma faculdade inteiramente natural do conhecimento que alcança a verdade sem necessidade de revelação sobrenatural $^{(4)}$.

É no século XIX que surgem dois grandes pensadores: Hegel (1770-1831) e Comte (1798-1857) que vão imprimir mudanças significativas no processo de conhecimento. 0 primeiro diz que tudo o que é real está submetido à razão e que 0 conhecimento é um movimento de três momentos que constituem a dialética hegeliana: a tese (posição), a antítese (negação) e a síntese (negação da negação, afirmação que nega e supera). Esse desenvolvimento é lógico e, ao mesmo tempo, histórico. Totalidade e processo são as noções fundamentais deste pensador ${ }^{(4)}$.

Comte é o fundador da filosofia positiva (o positivismo). Para Comte o único conhecimento aceitável é aquele que se constitui pela observação e pelas leis (manipulação da natureza). As noç̃̃es fundamentais para compreensão do positivismo são: Ordem e 
Progresso*. Atinge-se harmonia e movimento na medida em que progresso é sempre progresso na direção de uma ordem final. A lógica, a moral, a política e o conhecimento estão muito ligados. 0 saber positivo pretendia uma classificação e ordenação das ciências tradicionais $^{(1)}$.

0 positivismo considera a ciência como único conhecimento válido da realidade, defende a unidade metodológica estendendo a metodologia das ciências naturais ao campo das ciências humanas. A linguagem científica deve ser precisa, unívoca e objetiva, despida de conotações subjetivas. Privilegia os aspectos quantitativos da experiência $^{(5)}$.

Ainda no século XIX, temos como expoentes os trabalhos de Marx (1818-1883) e Engels (1820-1895) que se utilizaram da lógica dialética para analisar os fatos sociais, econômicos e políticos da sociedade européia. Para Marx a compreensão da sociedade devia basear-se na compreensão de suas relações econômicas, no entendimento de suas relações históricas, políticas e ideológicas. A base da sociedade são as condições materiais, sendo o trabalho a categoria essencial do pensamento marxista. É do e pelo trabalho que o homem se faz, constrói a sociedade, faz e transforma a história. A transformação da sociedade se dá por meio de contradições, antagonismo e conflitos. Não é linear, espontânea, mas é dada por saltos, sempre revolucionária. Marx afirma que não é a consciência dos homens que determina seu ser, mas, ao contrário, é o ser social que determina sua consciência. Sendo assim, o modo de produção da vida material condiciona o processo geral da vida social, política e econômica. 0 homem transforma a natureza para satisfação de suas necessidades e esse movimento é a contradição que precisa ser desvendada, entretanto, a síntese não é a solução definitiva da contradição, pois a solução já contém nova contradição ${ }^{(1)}$.

Os fenômenos constituem-se, fundam-se e transformamse a partir de múltiplas determinações que Ihes são essenciais; fazem parte de uma totalidade que os contém, que assim como o determina, é determinada por ele. Nesta concepção, a sociedade é um complexo de relações-movimento dialético e captar um fenômeno implica em captar a realidade em movimento.

0 método proposto por Marx deve permitir 0 desvendamento do fenômeno, descobrir por trás da aparência o fenômeno tal como realmente é, o que o determina. Não constituise nem como conhecimento especulativo (pois se refere ao real), nem como conhecimento contemplativo porque implica em transformar o real. Daí a noção de que o conhecimento científico envolve práxis ${ }^{(1)}$.

\section{PROBLEMAS METODOLÓGICOS}

A inserção do método no campo da saúde iniciou com o emprego do método das ciências naturais. Posteriormente, ocorre uma discussão a esse respeito já que existe uma diferenciação do objeto a ser investigado. Esse movimento indica que não cabe lidar com o social da mesma maneira que se lida com o natural. Há uma diferenciação entre um e outro. 0 objeto do social é o homem e suas relações, a sociedade. 0 objeto do método natural possibilita estudar os fenômenos sem relacioná-los, consiste numa seqüência de pensamento e prática que identifica problemas, formula solução especulativa, divide-a em unidades menores e comprova a veracidade do conjunto mediante experimentos e observações. Portanto, como pode-se perceber, a diferenciação a que nos referimos anteriormente é de natureza do objeto.

No campo da saúde, mais particularmente na área de Medicina Social, lida-se com o processo saúde-doença e as explicações pertinentes serão aquelas apropriadas à elucidação das características de manifestação de fenômenos histórico-sociais. Assim, implica na busca de explicações específicas (num dado tempo para uma dada sociedade). Dadas estas especificidades e lembrando que não há superioridade de um método sobre o outro, atualmente não se pode mais fazer uma transposição mecânica dos métodos e técnicas das ciências naturais para as ciências sociais.

Captar cientificamente a realidade na pesquisa social não é apreender o dado bruto, mas torná-lo um dado científico. Esta preocupação torna-se um problema de método. Assim, passaremos a discutir um pouco mais especificamente as questões relacionadas ao método nas ciência sociais.

Nesta área do conhecimento, a interpretação científica não compreende tomar os dados praticamente como reflexo da realidade. Antes, exige que se atinja um nível de profundidade e alcance da mesma procurando as relações com a totalidade na qual os fenômenos investigados se inserem. É importante estar alerta para o tipo de questão que é formulada numa investigação científica, pois as respostas a qualquer problema de natureza científica dependem de quais perguntas foram feitas e da sucessão dos porquês.

$\mathrm{Na}$ investigação científica, o esquema interpretativo, a teoria que a fundamenta, os procedimentos técnicos adequados são fundamentais. Afirma que: "As ciências sociais podem e devem utilizar todas as técnicas de análise qualitativa e quantitativa que fazem parte do acervo instrumental científico, mas o que não podem esquecer é que sua visão social só pode lhes assegurar o duplo caminho que parte do concreto real, passa pela abstração das

* Daqui saiu a inspiração das palavras da bandeira brasileira 
categorias analíticas, devolvendo um concreto pensado, que é o resultado de sua tarefa"(6).

0 real nunca é dado em sua aparência imediata, isso é somente a captação subjetiva dele. É preciso que o real seja objetivado, ou seja, romper a conexão entre real e sua captação subjetiva, objetivando-o. A apreensão imediata do real só pode dar-se por meio das percepções subjetivas, o que não constitui em conhecimento do real tal qual ele é ${ }^{(7)}$. 0 real é o concreto pensado, é a elaboração da interpretação da captação subjetiva de maneira objetiva. Assim, é impossível se pensar na premissa de externalidade entre sujeito e objeto do conhecimento, pois um está contido no outro.

Essa processualidade entre sujeito e objeto do conhecimento remete-nos ao componente específico das ciências sociais, a saber, o caráter histórico do objeto do conhecimento e o caráter histórico do sujeito e do conhecimento que é capaz de produzir. Assim, a aproximação entre investigador e objeto não pode ser neutra, mas necessariamente polarizada em relação às possibilidades históricas de (re)atualização daquela realidade. "0 andamento da pesquisa, em todas as suas fases, é capaz de impor correções e redefinições. (...) A pesquisa é processual, porque é processual a realidade a que ela se aplica"(7).

Outra questão importante refere-se ao conceito de causalidade. A busca da causa dos fenômenos deu-se na perspectiva de formulação de leis universais expressando as relações mecânicas entre os fenômenos. No estudo do social aparece como indicação de leis históricas, não mecânicas. Os fenômenos (sociais) constituem-se em parte de um movimento.

Apresentamos alguns dos problemas metodológicos que foram surgindo ao longo da história e que merecem atenção do pesquisador no campo da saúde pela especificidade e natureza de seu objeto. Num contexto em que diferentes métodos coexistem e em que a produção do conhecimento atinge uma velocidade tal que a variedade e quantidade de aplicações tecnológicas advindas da atividade científica, no campo da saúde, especificamente, e na sociedade em geral, aumentam incessantemente, verifica-se que estas mudanças colocam novos problemas metodológicos. Isso pode constituir-se em condição à geração de novos modelos metodológicos em resposta às questões que hoje se colocam, superando as alternativas até então propostas e gerando novos problemas $^{(1)}$.

Atualmente, discute-se os limites das abordagens teóricometodológicas apresentadas em captar a realidade social em movimento (formação e transformação). Entretanto, observa-se que as alternativas metodológicas apresentadas no século XX tem mais características de derivações das anteriores do que de rupturas que ultrapassem seus limites. São apresentadas num outro momento de desenvolvimento do capitalismo, o que leva a novos problemas e a busca da explicação precisa ser redimensionada neste novo contexto. A superação desses impasses metodológicos no campo da saúde poderá ser construída no debate teórico-metodológico que vem sendo realizado por estudiosos do assunto e no debate do cotidiano das práticas de saúde.

\section{CONSIDERAÇÕES FINAIS}

Tratar de questões metodológicas exige um conhecimento amplo e profundo da construção do conhecimento no campo da ciência e da filosofia. Explicar o movimento da sociedade requer mais do que conhecer questões econômicas, políticas e ideológicas de uma determinada sociedade em um determinado período, requer um compromisso com a transformação da sociedade, uma relação simbiótica entre o sujeito do conhecimento e o objeto a ser conhecido, assim como do conhecimento a ser produzido.

Desde o momento de inserção do método na ciência, como forma de produzir conhecimento, o debate acerca de seus limites e possibilidades vem sendo desenvolvido. Especificamente no campo da saúde, este debate é intensificado a partir da busca de metodologias qualitativas para conhecer e explicar os fenômenos desta área, com a preocupação de superação dos limites dos métodos das ciências naturais de captar a realidade social em movimento.

A apropriação destes referenciais metodológicos tem instrumentalizado pesquisas no campo da saúde ao mesmo tempo em que imprime discussões acerca dos limites e possibilidades das diversas modalidades de pesquisa qualitativa, dependendo da concepção que se tem de homem, natureza, sociedade. As diferenças de enfoque de uma modalidade para outra são intimamente ligadas às distintas trajetórias percorridas em direção aos fundamentos de respostas relacionadas às questões do método.

No campo da saúde, o movimento de emprego de metodologias qualitativas é relativamente recente, mas já apresenta uma vasta produção científica de qualidade reconhecível, principalmente na área de medicina social.

Os problemas metodológicos de investigação neste campo vão sendo apresentados na própria dinâmica da produção de conhecimento em uma sociedade em constante transformação. A superação destes problemas não está dada e nem pode ser utilizada de forma prescritiva na prática cotidiana da pesquisa. Mas as possibilidades poderão ser construídas dentro desta dinâmica, no debate coletivo com vistas a busca de "novas" formas de apreensão, compreensão e explicação dos fenômenos no campo da saúde. 


\section{REFERÊNCIAS BIBLIOGRÁFICAS}

1. Andrey MA, Micheletto N, Sério TMP, Rubano DR, Moroz M, Pereira ME, et al. Para compreender a ciência: uma perspectiva histórica. $6^{a}$ ed. Rio de Janeiro (RJ): Espaço e Tempo; 1996.

2. Foucault M. 0 nascimento da medicina social. In: Microfísica do poder. 10a ed. Rio de Janeiro (RJ): Graal; 1972.

3. Nunes ED. Saúde coletiva: revisitando a sua história e os cursos de pós-graduação. Rev Ciência e Saúde Coletiva 1996; 1 (1):55-69.

4. Chauí M. Convite à filosofia. São Paulo (SP): Ática; 1994.
5. Rocha SMM, Silva GB da. Linhas filosóficas e ideológicas na pesquisa em enfermagem no Brasil. Rev Bras Enfermagem 1987 out./dez; 40(4):214-21.

6. Testa M. Pensar em saúde. Porto Alegre (RS): Artes Médicas; 1992.

7. Gonçalves RBM. 0 processo da pesquisa, as questões teóricas e metodológicas. In: Tecnologia e organização social das práticas de saúde: características tecnológicas de processo de trabalho na rede estadual de centros de saúde de São Paulo. São Paulo (SP): HucitecAbrasco; 1994. p.15-54. 